\title{
BMJ Open The North Texas Concussion Registry (ConTex)
}

\author{
C. Munro Cullum (D) , ${ }^{1,2,3}$ Stephen Bunt (D) , ${ }^{1}$ Cason Hicks, ${ }^{1}$ Nyaz Didehbani (D) , \\ Shane Miller (1) , ${ }^{4,5}$ Bert Vargas, ${ }^{2}$ Tonia Sabo, ${ }^{2}$ Kathleen Bell, ${ }^{6}$ H Hunt Batjer ${ }^{3}$
}

To cite: Cullum CM, Bunt S, Hicks C, et al. The North Texas Concussion Registry (ConTex). BMJ Open 2020;10:e032345. doi:10.1136/ bmjopen-2019-032345

- Prepublication history and additional material for this paper are available online. To view these files, please visit the journal online (http://dx.doi. org/10.1136/bmjopen-2019032345).

Received 13 June 2019 Revised 25 0ctober 2019 Accepted 10 December 2019

D Check for updates

(C) Author(s) (or their employer(s)) 2020. Re-use permitted under CC BY-NC. No commercial re-use. See rights and permissions. Published by BMJ.

For numbered affiliations see end of article.

\section{Correspondence to} Dr Stephen Bunt; stephen.bunt@utsouthwestern. edu

\section{ABSTRACT}

Purpose The North Texas Concussion Registry (ConTex) was established in 2015 as a multi-institutional collaboration intended to study risk factors, recovery patterns and clinical outcomes associated with concussion across the lifespan, with a particular emphasis on sportrelated concussion.

Participants Prospective enrolment of individuals who sustained a concussion within the past 6 months who were seen at one of four North Texas ConTex concussion clinics which employ common diagnostic criteria and assessment metrics to evaluate effects of a concussion as well as longitudinal tracking of recovery.

Findings to date The ConTex database and multidisciplinary oversight team has been established, and over 1700 participants aged 5-88 years have been enrolled. A majority of concussions were sport-related $(60 \%)$, with a mean age of 17.5 years and similar numbers of males and females. Three-month follow-up compliance has been excellent (86\%), with a majority of subjects reporting good recovery by that time. ConTex has provided a rich data source for multiple research projects focused on concussion characteristics, risk factors and outcomes, and led to the development of a statewide youth concussion registry.

Future plans ConTex data are being analysed to add to the body of knowledge regarding concussion mechanisms, factors related to recovery and improving outcomes for concussion patients. ConTex will serve as a platform for future treatment studies and may serve as a model for other concussion surveillance programmes.

\section{INTRODUCTION}

The Centers for Disease Control (CDC) estimates that there are over 3.8 million concussions annually, with some 2.5 million US students in grades 9-12 sustaining a sportrelated concussion (SRC) each year. ${ }^{12}$ These CDC estimates of concussions are based on cases reporting to emergency departments, and likely represent only a proportion of all concussions, as many go unrecognised, unreported or present to general practitioners or specialty clinics. ${ }^{2}$ Due in part to growing awareness in professional sports and publicity from high-profile athletes, SRC has received increasing attention in recent years. ${ }^{2-4}$ Despite a dramatic increase in concussion-related

\section{Strengths and limitations of this study}

This is a large prospective longitudinal study of concussion, which includes a wide range of age and injury mechanisms to allow for robust data analysis of variables including age, sex, injury mechanism, risk factors, symptoms, objective test results and recovery metrics using standardised assessment tools at initial clinical assessment and 3-month follow-up.

- The study design, oversight team structure, methods of data capture and variables relevant to concussion may serve as a model for other concussion surveillance programmes.

- Enrolment of subjects from multiple clinical sites and involvement of varied providers allows for a real-world analysis of concussion assessment and management.

- The variety of clinicians across several sites could lead to variance in outcomes, although standardisation of procedures, regular meetings of site leadership and routine monitoring of data quality are in place to address this.

- Data collection is from four primary concussion clinics in North Texas, with limited sample diversity, a reliance on self-report instruments and an emphasis on sport-related concussion; thus, extension to other populations will be important.

research, relatively little is known about the true epidemiology, risk factors and predictors of recovery. ${ }^{35}$ Multiple studies have reported increased concussion rates over time, although this may be due to greater vigilance and awareness of SRC. ${ }^{6}$ Although there are a number of large concussion studies, many do not reflect clinical practice, are limited in scope/depth, are retrospective and/or are designed around global injury-related or specific investigative efforts (eg, geared towards more serious traumatic brain injuries (TBIs) or specific age ranges).$^{7-11}$

In order to help address these gaps in knowledge, the North Texas Concussion Registry (ConTex) was launched in the fall of 2015. The goal of this project is to prospectively obtain detailed information from participants across the lifespan who sustain a concussion in order to study local concussion 
trends, demographic factors, injury mechanisms, clinical outcomes and identify risk factors for prolonged recovery. Although the focus of ConTex is on SRC, and participating clinics were selected to reflect this emphasis, nonSRC injuries are also included to allow for analysis and comparison of various mechanisms and trends.

\section{Cohort description}

\section{Study design and overview}

ConTex is a longitudinal cohort study that includes an initial injury and clinical characterisation component and a 3-month follow-up. Participants are recruited from local concussion clinics in the North Texas area, including Texas Scottish Rite Hospital for Children, Children's Health, the University of Texas Southwestern Medical Center and Texas Health Resources Ben Hogan Sports Medicine (recruitment from the Texas Health Resources ceased 1 October 2017 when the clinic closed for reasons unrelated to our study). Primary care physicians, athletic trainers, team physicians, school nurses and emergency department physicians determine an initial diagnosis or suspicion of a concussion and then refer the potential subject to a ConTex clinic, where patients are seen as a part of routine clinical care and whose staff include faculty from the University of Texas Southwestern Medical Center. ConTex providers trained in the recognition and treatment of concussion then determine a diagnosis of concussion based on the Berlin Consensus Statement, ${ }^{12}$ an internationally accepted concussion resource. If a subject receives a concussion diagnosis and also meets ConTex eligibility criteria (table 1 ), they are informed of the study by ConTex personnel during their initial clinic visit. Those who express interest in participating provide written informed consent (assent is obtained from minors in addition to consent from parents or legal guardian) (see online supplementary file).

\section{Table 1 ConTex inclusion/exclusion criteria}

\begin{tabular}{|c|c|}
\hline Inclusion criteria & Exclusion criteria \\
\hline Age 5 and over & $\begin{array}{l}\text { Loss of consciousness } \\
\text { (LOC) lasting }>30 \mathrm{~min}\end{array}$ \\
\hline $\begin{array}{l}\text { Diagnosis of concussion } \\
\text { presenting at participating clinic }\end{array}$ & $\begin{array}{l}\text { Known skull fracture or } \\
\text { intracranial bleed }\end{array}$ \\
\hline Fluency in English & $\begin{array}{l}\text { Most recent concussion } \\
\text { occurring }>6 \text { months ago }\end{array}$ \\
\hline $\begin{array}{l}\text { Visual acuity/hearing adequate } \\
\text { for completing interviews and } \\
\text { questionnaires }\end{array}$ & $\begin{array}{l}\text { Spinal cord injury with } \\
\text { American Spinal Injury } \\
\text { Association (ASIA) score of } \\
\text { C or worse }\end{array}$ \\
\hline $\begin{array}{l}\text { Ability to provide informed } \\
\text { consent, and in cases of } \\
\text { minors, ability to provide } \\
\text { assent+legal representative } \\
\text { available to provide informed } \\
\text { consent }\end{array}$ & \\
\hline
\end{tabular}

ConTex, The North Texas Concussion Registry.
Each ConTex site has a designated site leader that serves on the ConTex Steering Committee, which provides scientific oversight to the project. This multidisciplinary group meets quarterly to review study progress, recruitment issues, scientific review of data and vetting of new projects as they are proposed. Each ConTex site also has a research coordinator that is responsible for screening and consenting participants, conducting semi-structured interviews, administering questionnaires and inputting data at the initial visit.

Data collected during the initial visit include information obtained from participants, parents/guardians as applicable and a review of the medical record (injury characteristics, concussion history, demographics, personal and family medical history, etc). Subjects are included if they have sustained a concussion within the past 6 months in order to provide a realistic depiction of concussion referrals to our clinics and to allow for a broader analysis of data and groups based on time-since-injury. Additional information specific to SRC such as level of play (school/ club), activity at time of injury (game/practice) and sportspecific factors (helmet/no helmet) are recorded. Participants complete questionnaires that address some of the major clinical outcome domains of interest, including screening for depression, anxiety, sleep quality and current symptoms. Treatment and recovery information (eg, what treatments were prescribed, duration of symptoms and extent to which subjects feel they have recovered, etc) is also collected. Parents are asked to complete questionnaires on behalf of their children for subjects under age 12, and a primary email address and phone number is obtained for follow-up participation.

Three months following the initial clinical visit, an email notice is sent to participants that includes a link to a secure database consisting of a subset of questionnaires administered at the initial visit in addition to questions regarding symptom recovery, return to play/normal activity timeline and functional status. Telephone contact is made if subjects do not complete online follow-up materials. Participants are compensated US $\$ 15$ at enrolment and another US\$25 after completion of the online follow-up via a Visa debit card (Greenphire ClinCard).

\section{Data collection}

ConTex was designed as a flexible data collection platform, allowing for special projects as they develop while maintaining core variable collection. ConTex uses Research Electronic Data Capture (REDCap), ${ }^{13}$ which provides a secure, HIPAA-compliant database with userfriendly data entry, error checking capabilities and allows exporting for statistical analysis. Each ConTex site maintains necessary identifiers to ensure quality and proper follow-up in accordance with IRB policy. Study personnel at each site enter data directly into REDCap from the electronic medical record and during an in-person semistructured interview with participants to ensure data uniformity and integrity. Data entered in the database are monitored by a Data Specialist using a REDCap data 


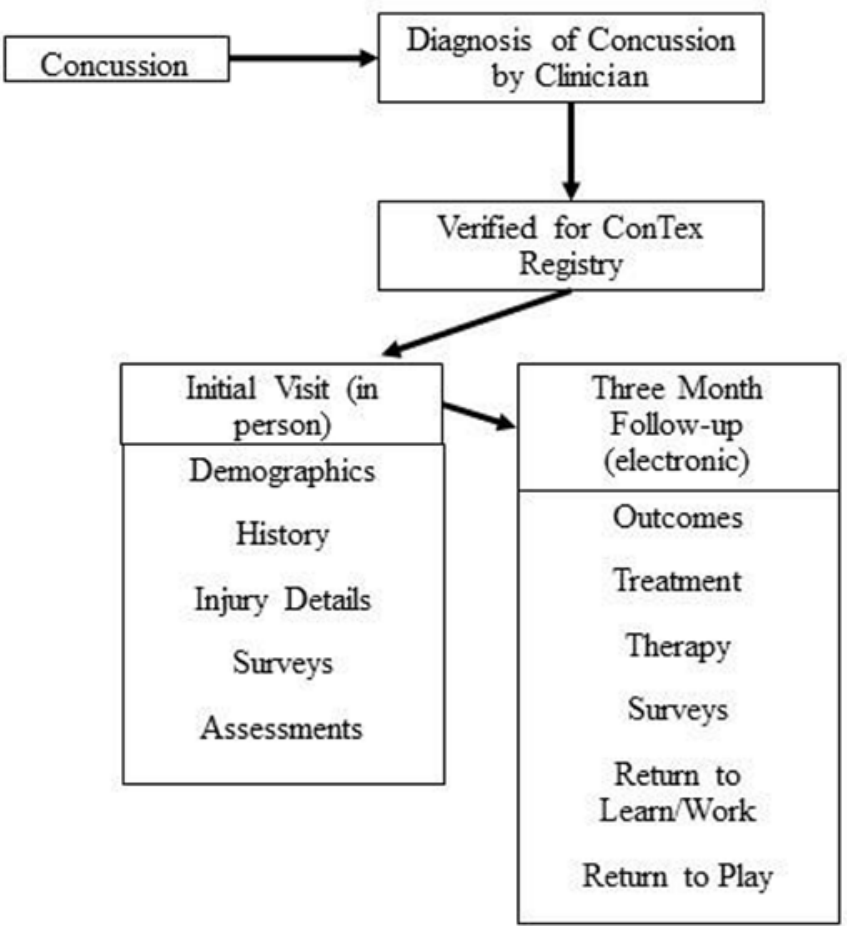

Figure 1 TheNorth Texas Concussion Registry (ConTex) data flow.

quality control module that reports missing values, validation errors and outliers. The ConTex Scientific Review Committee, consisting of co-investigators and coordinators, monitors projects, manages changes in study procedures and authorises research proposals and data access. Figure 1 provides an overview of the flow of ConTex data.

\section{ConTex variables}

Table 2 provides a summary of the core measures being uniformly collected across ConTex sites by trained research coordinators under the supervision of site principal investigators.

Each ConTex clinic collects a core set of measures: the Concussion Symptom Log (a subset of the Sport Concussion Assessment Tool or SCAT5/ChildSCAT5, depending on subject age) to record symptoms, ${ }^{14}$ the Generalised Anxiety Disorder 7-item Scale to assess anxiety symptoms, ${ }^{15} 16$ Patient Health Questionnaire-8 (PHQ-8) to assess depressive symptoms ${ }^{17}$ and the Pittsburgh Sleep Quality Index to assess sleep quality over the past month ${ }^{18}$ because sleep disturbance is common following concussion. ${ }^{19}$ Approximately $92 \%$ of participants have completed all core measures.

As part of each clinic's routine concussion assessment procedure, balance is tested by one of three measures: the Balance Error Scoring System (BESS), an observerscored balance test commonly used to assess $\mathrm{SRC}^{20}$; the shortened version of the BESS, the Modified Balance Error Scoring System (mBESS) ${ }^{21}$ or the Sway Balance test, which objectively measures balance using a computer tablet or smartphone and has a strong correlation with
Table 2 Primary ConTex measures

\begin{tabular}{lll}
\hline Measure & $\begin{array}{l}\text { Postinjury } \\
\text { visit }\end{array}$ & $\begin{array}{l}\text { 3-month follow- } \\
\text { up }\end{array}$ \\
\hline $\begin{array}{l}\text { SCAT 5 Concussion } \\
\text { Symptom Log }\end{array}$ & $\checkmark$ & $\checkmark$ \\
$\begin{array}{l}\text { Anxiety (GAD-7) } \\
\text { Depression (PHQ-8) }\end{array}$ & $\checkmark$ & $\checkmark$ \\
Sleep quality (PSQI) & $\checkmark$ & $\checkmark$ \\
BESS/mBESS/sway & $\checkmark$ & $\checkmark$ \\
balance & $*$ & \\
ImPACT & $*$ & \\
King-Devick & $*$ \\
Brief Resilience Scale & $*$ \\
Sideline Assessment of \\
Concussion \\
$\begin{array}{l}\text { Acute Concussion } \\
\text { Evaluation }\end{array}$
\end{tabular}

$\checkmark$ Collected as part of core ConTex protocol.

${ }^{*}$ Collected if available in the individual clinic.

BESS, Balance Error Scoring System; ConTex, The North Texas Concussion Registry ; GAD-7, Generalised Anxiety Disorder 7item Scale; ImPACT, Immediate Post-Concussion Assessment and Cognitive Testing; mBESS, Modified Balance Error Scoring System; PHQ-8, Patient Health Questionnaire-8; PSQI, Pittsburgh Sleep Quality Index.

the BESS $(\mathrm{r}=-0.77)$, and has demonstrated good testretest reliability. 223

As a flexible data collection platform, ConTex can collect a wide range of measures that may be used in individual participating clinics at the discretion of the site principal investigators. These additional assessments vary across sites and may vary over time, but ConTex collects the data when available. Neurocognitive functioning is assessed in some of the ConTex clinics using the Immediate Post-Concussion Assessment and Cognitive Testing (ImPACT), a computer-administered battery of cognitive ability tests. ${ }^{24}$ When available, subjects' baseline and postinjury ImPACT data are collected. Visual processing/ attention is assessed at some ConTex sites with the KingDevick test, a brief timed measure of visual tracking. ${ }^{25} 26$ The Brief Resilience Scale is used to measure an individual's self-reported resistance and response to various health or injury-related setbacks. ${ }^{27} 28$ The Standardised Assessment of Cognition, ${ }^{14}$ another portion of the SCAT5, is also sometimes used to assess an injured athlete's mental status. Lastly, the Acute Concussion Evaluation ${ }^{29}$ is also used in the evaluation of injury at some clinics.

Results from neuroimaging and other diagnostic procedures are also collected and added to the ConTex database when available in order to facilitate the development of pilot data for research projects. Likewise, investigators may propose the addition of specialised assessments or data collection tools for specific research questions or pilot data. If approved by the Steering Committee, those 


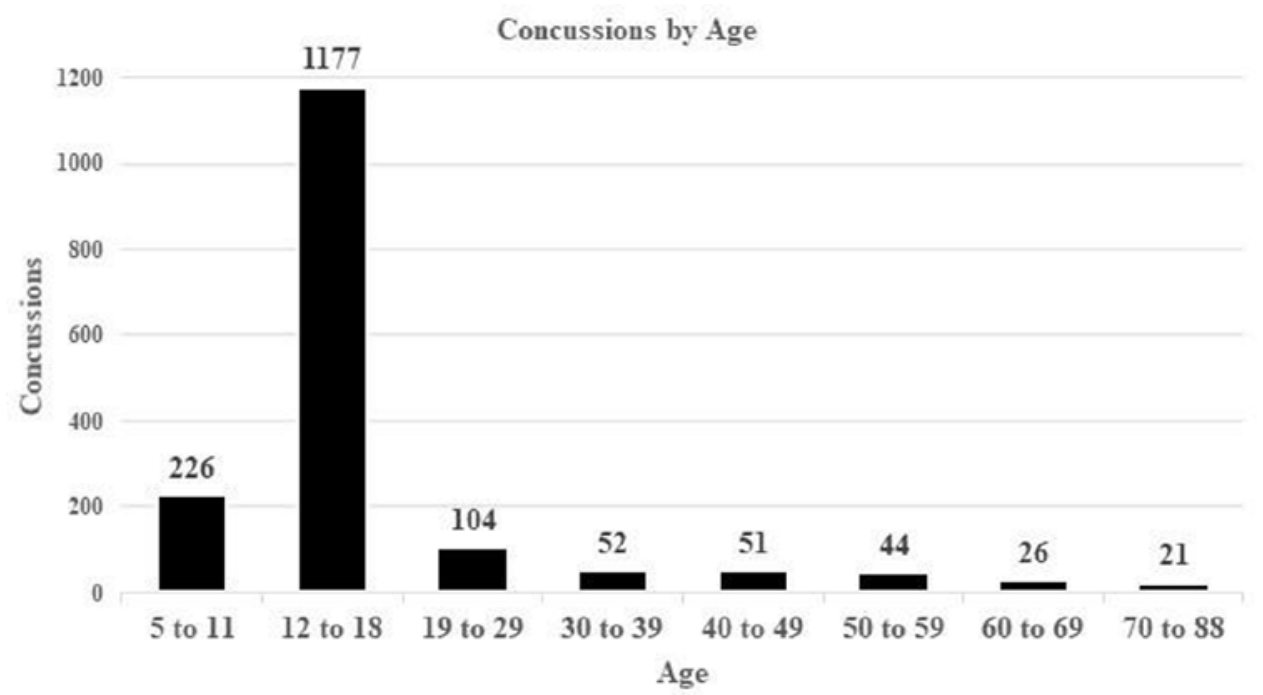

Figure 2 TheNorth Texas Concussion Registry concussions by age.

measures will be included for a specified time point or for a specified number of subjects, with findings reviewed by the group to see if there is interest in continuing those measures. Annually, all assessment tools included in ConTex are reviewed and a consensus of investigators determines whether various instruments will be dropped or added to the protocol.

\section{Patient and public involvement}

ConTex was designed by the multidisciplinary research team without patient or public involvement nor were patients invited to contribute to the writing of this document.

\section{Findings to date}

As of May 2019, 1701 subjects have been enrolled in the ConTex registry. Since we began keeping screening statistics in May 2018, 43\% of all patients seen in ConTex clinics with suspected concussions were enrolled. Of those who were not enrolled, $38 \%$ did not meet inclusion criteria (of those excluded, $58 \%$ were seen $>6$ months postinjury, $17 \%$ had a more serious TBI, $12 \%$ were determined in clinic to not have a diagnosis of concussion and $6 \%$ were not fluent in English).

Of the 1701 subjects enrolled since the beginning of ConTex in 2015, there were approximately equal percentages of female (52\%) and male subjects $(48 \%)$, a mean age of 17.5 years and median age of 15 years (range 5-88) (figure 2). Subjects between ages 12 and 18 comprised $70 \%$ of all participants. The ethnic makeup of subjects was $82 \%$ non-Hispanic and $18 \%$ Hispanic. Regardless of ethnicity, almost $80 \%$ of subjects identified as white, and those identifying as black or African-American comprised the second largest racial group at nearly $15 \%$. High school students comprised the largest group of ConTex subjects (47\%), with middle school students (24\%) as the second largest group. Nineteen per cent of ConTex subjects were college graduates.
Thus far, SRCs account for $60 \%$ of all concussions recorded (table 3), with most occurring in tackle football $(27 \%)$ and soccer $(22 \%)$, followed by basketball (13\%), volleyball (7\%), cheerleading (4\%) and softball (3\%). Among non-SRCs, motor vehicle accidents, falls and hitting/being hit with an object accounted for the most concussions.

A primary goal of ConTex is to collect quality data at subjects' initial clinical visit and again at a 3-month follow-up to capture information regarding recovery. The median time from injury to enrolment was 6 days, with $71 \%$ of initial evaluations occurring within 30 days of injury. A majority of subjects $(63 \%)$ are referred to a ConTex clinic from either emergency personnel or an athletic trainer that provided a preliminary assessment prior to the ConTex clinical evaluation (see table 4 for a list of primary provider types referring patients to ConTex). Of those eligible for follow-up (ie, subjects that are 3 months postinitial ConTex visit), the completion rate was $86 \%$. By that time, $81 \%$ of these subjects reported feeling 'back to normal', which is consistent with general concussion recovery statistics. ${ }^{30}$

\section{DISCUSSION}

Recent increases in concussion awareness have led to a substantial increase in concussion research worldwide. Although much has been learnt, a number of important questions remain unanswered, and work in this area is in its early stages. SRC, in particular, has gained attention in recent years with a general focus being on football and male sports. Knowledge gaps exist concerning presenting features, risk and recovery factors and differences in treatment and recovery patterns in females and across various age ranges and types of injuries. ConTex is broad in its enrolment, with the goal of obtaining a balanced assessment regardless of sex, age, injury mechanisms and pre-existing factors. This inclusive enrolment strategy 
Table 3 Mechanism of injury

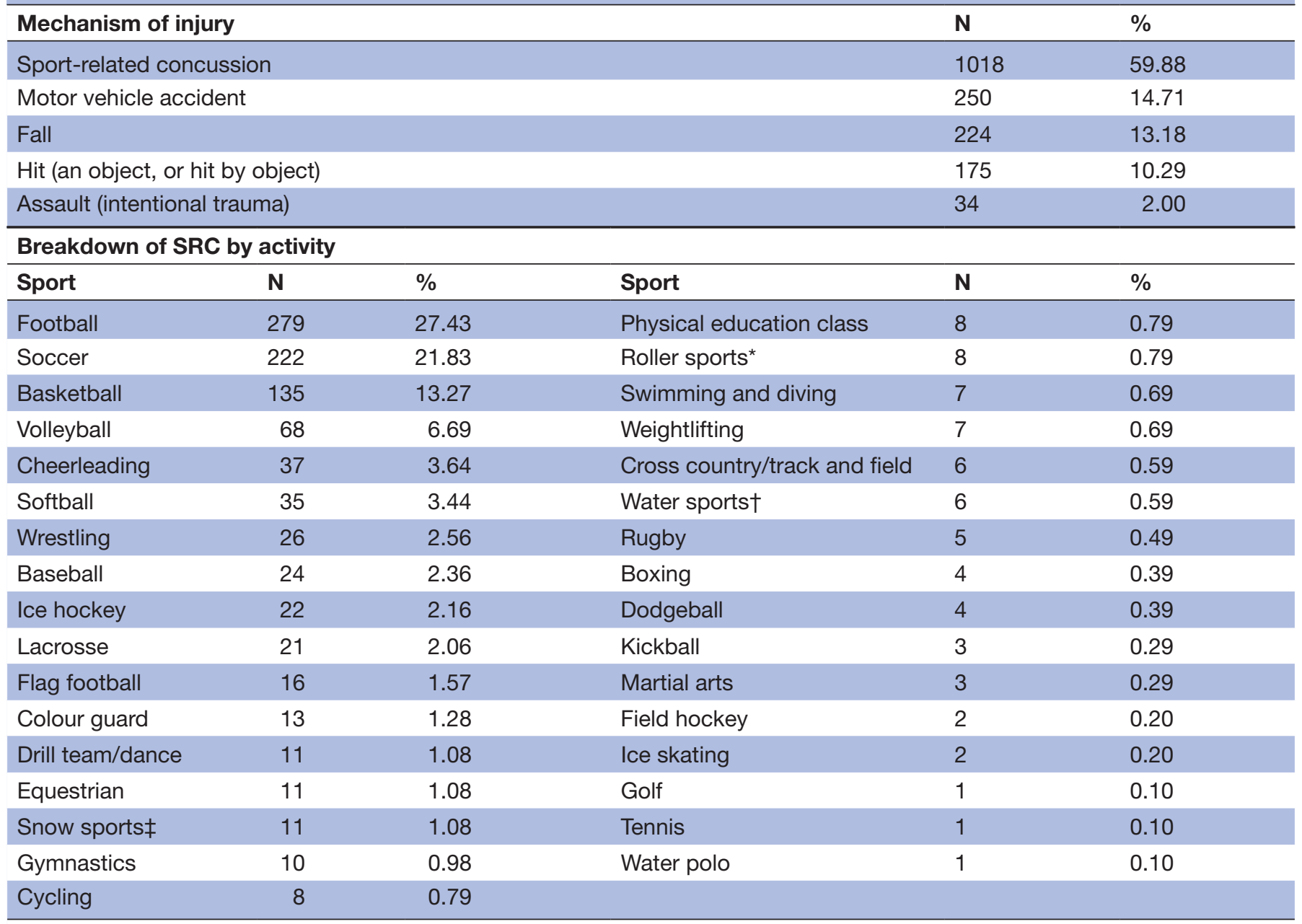

${ }^{*}$ Roller skating, skateboarding. †Waterskiing, jet ski.

‡Snow skiing, snowboarding.

SRC, sport-related concussion.

helps to elucidate factors that may influence early identification of specific premorbid and comorbid factors that characterise individuals who may be at increased risk for prolonged symptoms. This growing data bank from over

\begin{tabular}{lc}
\hline \multicolumn{2}{l}{ Table 4 Providers of initial concussion assessment } \\
\hline Initial assessment performed by: & $\%$ \\
\hline Emergency personnel & 35.23 \\
Athletic trainer & 27.39 \\
Family doctor or primary care physician & 14.74 \\
Coach & 7.53 \\
ConTex clinic (first assessment) & 7.09 \\
School nurse & 5.98 \\
Other & 1.42 \\
Team doctor & 0.62 \\
\hline
\end{tabular}

ConTex, The North Texas Concussion Registry.
1700 subjects begins to allow for sufficient sample sizes to engage in quality data analysis, which may lead to a better understanding of how to identify key symptoms, risk factors and improve recovery and likelihood that patients return to baseline.

Several manuscript workgroups within the ConTex research team include premorbid risk factors, psychological factors in symptom maintenance, headache, sex differences, ${ }^{31}$ sleep $^{32}$ and models for recovery prediction following SRC. A future goal of ConTex is to establish an effective framework for studies aiming to evaluate assessment, surveillance and treatment of concussion as well as the critical evaluation of diagnostic technologies as they are developed to advance the field of concussion research. Another future goal is to improve the specificity of symptom diagnoses within the dataset. For example, this includes efforts to further categorise 'headache' into specific phenotypes (ie, migraine, tension-type, etc), to identify specific causes for impaired sleep quality (ie, central sleep apnoea, obstructive sleep apnoea, iatrogenic 
causes, etc), and to better characterise risk and recovery factors related to premorbid personality, psychological status and resilience.

ConTex may serve as a model for other local, statewide and national concussion studies in order to aid in the understanding of concussion, its frequency and risk and recovery factors across a wide age range and multiple mechanisms of injury. An important outgrowth of ConTex has been the development and implementation of a statewide concussion registry for public schools through a collaboration between the University of Texas Southwestern Medical Center and the governing body of public school athletics in Texas, the University Interscholastic League, which will be described in a separate report.

\section{Strengths and limitations}

Other large prospective sports injury databases exist ${ }^{10}{ }^{11}$; however, few focus specifically on concussion and capture detailed concussion and recovery characteristics in both sexes across the lifespan over time. ConTex is also unique in that the team has established an easy-to-use database, common data collection procedures, a proactive research oversight team and dedicated workgroups with special interests in various aspects of concussion and recovery.

Despite a roughly even balance of males and females, our ethnic/racial representation is currently limited. According to 2018 population estimates, 29\% of the North Texas area was identified as Hispanic, ${ }^{33}$ although only $18 \%$ of those enrolled in ConTex were identified as Hispanic. This may reflect the geographic locations of ConTex clinics as only 25 subjects were excluded due to non-fluency in English (a requirement since most of the standard questionnaires have not yet been validated in Spanish). Other factors that may limit ConTex diversity include location of our clinics, community concussion awareness and regional interests in research participation. ConTex investigators are attempting to address these limitations through the translation of assessment materials and raising concussion awareness through outreach events in the community via health fairs and school presentations.

Similarly, there may be a sampling bias to ConTex data at this point. While most participants were evaluated within 2 weeks of concussion, $30 \%$ presented $>30$ days after injury and $>250$ potential subjects were excluded due to their injuries occurring $>6$ months prior. The current ConTex clinical providers represent specialists and tertiary care providers, and as such, patients often present in the subacute or chronic phase of injury. This population is more likely to still be experiencing symptoms and may disproportionally represent those with prolonged recovery. While this might be a limitation of the overall data to date, it affords a unique opportunity to examine the characteristics of specific cohorts within our larger dataset, that is, those who have persistent symptoms, which is a group in need of particular research attention since less is known about this sizeable minority of concussed individuals.
Although many symptom measures such as those used in ConTex are based on self-report and cannot be externally validated, they are globally accepted and widely used tools for research and clinical application. We did not include specific symptom validity measures, but participants had no obvious motivation to deny or enhance symptom reporting as they had already received a clinical diagnosis of concussion prior to data collection, and all were recruited for ConTex as a part of routine clinic visits. It is through future research efforts such as those afforded by ConTex that less reliance on subjective assessment of concussions such as self-reporting and more reliance on objective measures for assessment of concussion can be developed and validated.

ConTex is an interdisciplinary, multi-institutional project, representing the combined efforts of doctorallevel scientist-practitioners in the areas of neurology, physical medicine and rehabilitation, neuropsychology, neurosurgery and sports medicine from four Dallas-area academically affiliated concussion clinics. Collection of data from multiple sites, by clinicians with varied backgrounds could present limitations to reliability and generalisability, although ConTex has addressed this by use of common definitions and procedures agreed on by site leaders with regular review and monitoring of procedures and data for quality control. ConTex clinicians adhere to a consensus-based multimodal approach to the evaluation and treatment of concussions. ${ }^{1234}$ This approach allows ConTex to replicate the 'real world' of clinical practice.

\section{Collaboration}

ConTex findings are disseminated at scientific conferences, local lectures and through peer-reviewed journals. The database provides an investigative repository for ConTex investigators for analyses. There are no plans to disseminate ConTex data to study participants per se outside the aforementioned scientific outlets.

\section{Author affiliations}

${ }^{1}$ Department of Psychiatry, University of Texas Southwestern Medical Center, Dallas, Texas, USA

${ }^{2}$ Department of Neurology and Neurotherapeutics, University of Texas Southwestern Medical Center, Dallas, Texas, USA

${ }^{3}$ Department of Neurological Surgery, University of Texas Southwestern Medical Center, Dallas, Texas, USA

${ }^{4}$ Departments of Orthopedics and Sports Medicine, Texas Scottish Rite Hospital, Dallas, Texas, USA

${ }^{5}$ Departments of Orthopaedic Surgery and Pediatrics, University of Texas Southwestern Medical Center, Dallas, TX, United States

${ }^{6}$ Physical Medicine and Rehabilitation, University of Texas Southwestern Medical Center, Dallas, Texas, USA

Twitter C. Munro Cullum @Munro_CullumPhD, Stephen Bunt @StephenCBunt and Nyaz Didehbani @DidehbaniNyaz

Collaborators ConTex collaborators include: (1) Texas Scottish Rite Hospital: Shane Miller MD, Jane Chung MD, Aaron Zynda BS CCRP, Megan Sabatino BS, CCRP; (2) Children's Medical Center: Tonia Sabo MD, Marsha Siebenmorgen PhD, Mathew Stokes MD; (3) UT Southwestern Medical Center: C. Munro Cullum PhD, Hunt Batjer MD, Kathleen Bell MD, Bert Vargas MD, Nyaz Didehbani PhD, Heidi Rossetti PhD, Mark Goldberg MD, Chris Paliotta MBA, Linda Hynan PhD, Charlene Supnet PhD, Bruce Jones PhD, Stephen Bunt EdD, Elida Godbey MRC, Cason Hicks MS, Sarah 
Sprinkle MA, Doris Escobedo MS, Caryn Harper MS, Nasreen Sayed MS, Tahnae Tarkenton MCRC.

Contributors MC is the Principal Investigator for the ConTex study. SM, BV, TS, KB and $\mathrm{HHB}$ are Co-investigators and clinical directors at ConTex clinics. SB and $\mathrm{CH}$ are ConTex Research Coordinators. MC, SB, CH, ND, SM, BV, TS, KB and HHB developed the ConTex protocol and study design. $\mathrm{MC}, \mathrm{SB}$ and $\mathrm{CH}$ drafted the initial manuscript. $\mathrm{SB}$ and $\mathrm{CH}$ were responsible for data collection and analysis. All authors provided input on reporting of initial study findings. All authors participated in revision and gave approval of the published version.

Funding This prospective registry was funded by a grant from the Texas Institute for Brain Injury and Repair (TIBIR), a state-funded initiative as part of the Peter J. O'Donnell Jr. Brain Institute at The University of Texas Southwestern Medical Center. Competing interests None declared.

Patient consent for publication Not required.

Ethics approval This study was approved by the UT Southwestern Institutional Review Board (STU 012015-032) and the Texas Health Resources Institutional Review Board (Pro00006054).

Provenance and peer review Not commissioned; externally peer reviewed.

Data availability statement Data are not publicly available at this time.

Open access This is an open access article distributed in accordance with the Creative Commons Attribution Non Commercial (CC BY-NC 4.0) license, which permits others to distribute, remix, adapt, build upon this work non-commercially, and license their derivative works on different terms, provided the original work is properly cited, appropriate credit is given, any changes made indicated, and the use is non-commercial. See: http://creativecommons.org/licenses/by-nc/4.0/.

\section{ORCID iDs}

C. Munro Cullum https://orcid.org/0000-0001-9706-5465

Stephen Bunt http://orcid.org/0000-0002-3631-4648

Nyaz Didehbani http://orcid.org/0000-0001-6121-5759

Shane Miller http://orcid.org/0000-0001-5002-5095

\section{REFERENCES}

1 DePadilla L, Miller GF, Jones SE, et al. Self-reported concussions from playing a sport or being physically active among high school students - United States, 2017. MMWR Morb Mortal Wkly Rep 2018:67:682-5.

2 Daneshvar DH, Nowinski CJ, McKee AC, et al. The epidemiology of sport-related concussion. Clin Sports Med 2011;30:1-17.

3 Pfister T, Pfister K, Hagel B, et al. The incidence of concussion in youth sports: a systematic review and meta-analysis. $\mathrm{Br} J$ Sports Med 2016;50:292-7.

4 Lincoln AE, Caswell SV, Almquist JL, et al. Trends in concussion incidence in high school sports: a prospective 11-year study. Am J Sports Med 2011;39:958-63.

5 Teel EF, Marshall SW, Shankar V, et al. Predicting recovery patterns after sport-related concussion. J Athl Train 2017;52:288-98.

6 Gessel LM, Field SK, Collins CL, et al. Concussions among United States high school and collegiate athletes. J Ath Train 2007;42:495-503.

7 Marshall SW, Guskiewicz KM, Shankar V, et al. Epidemiology of sports-related concussion in seven US high school and collegiate sports. Inj Epidemiol 2015;2.

8 Amoo-Achampong K, Rosas S, Schmoke N, et al. Trends in sports-related concussion diagnoses in the USA: a populationbased analysis using a private-payor database. Phys Sportsmed 2017:45:239-44.

9 Wallace J, Covassin T, Beidler E. Sex differences in high school athletes' knowledge of sport-related concussion symptoms and reporting behaviors. J Athl Train 2017;52:682-8.

10 Broglio SP, McCrea M, McAllister T, et al. A national study on the effects of concussion in collegiate athletes and US military service Academy members: the NCAA-DoD concussion assessment, research and education (care) Consortium structure and methods. Sports Med 2017:47:1437-51.

11 Kerr ZY, Comstock RD, Dompier TP, et al. The first decade of webbased sports injury surveillance (2004-2005 through 2013-2014): methods of the National collegiate athletic association injury surveillance program and high school reporting information online. $J$ Athl Train 2018;53:729-37.

12 McCrory P, Meeuwisse W, Dvorak J, et al. Consensus statement on concussion in sport - the 5th international conference on concussion in sport held in Berlin, October 2016. Br J Sports Med 2017:26:838-47.

13 Harris PA, Taylor R, Thielke R, et al. Research electronic data capture (REDCap)-A metadata-driven methodology and workflow process for providing translational research informatics support. J Biomed Inform 2009;42:377-81.

14 Echemendia RJ, Meeuwisse W, McCrory P, et al. Sport concussion assessment tool - 5th edition. Br J Sports Med 2017;51:851-8.

15 Spitzer RL, Kroenke K, Williams JBW, et al. A brief measure for assessing generalized anxiety disorder. Arch Intern Med 2006;166:1092-7.

16 Löwe B, Decker O, Müller S, et al. Validation and standardization of the generalized anxiety disorder screener (GAD-7) in the general population. Med Care 2008;46:266-74.

17 Kroenke K, Spitzer RL. The PHQ-9: a new depression diagnostic and severity measure. Psychiatr Ann 2002;32:509-15.

18 Buysse DJ, Reynolds CF, Monk TH, et al. The Pittsburgh sleep quality index: a new instrument for psychiatric practice and research. Psychiatry Res 1989;28:193-213.

19 Bramley H, Henson A, Lewis MM, et al. Sleep disturbance following concussion is a risk factor for a prolonged recovery. Clin Pediatr 2017;56:1280-5.

20 Giza CC, Kutcher JS, Ashwal S, et al. Summary of evidence-based guideline update: evaluation and management of concussion in sports: report of the Guideline Development Subcommittee of the American Academy of Neurology. Neurology 2013;80:2250-7.

21 Iverson GL, Koehle MS. Normative data for the modified balance error scoring system in adults. Brain Injury 2013;27:596-9.

22 Patterson JA, Amic RZ, Thummar T, et al. Validations of measures from the smartphone sway balance application: a pilot study. Int $J$ of Sports Phys Ther 2014;9:135-9.

23 Amick RZ, Jansen SD, Chaparro A, et al. Comparison of the sway balance mobile application to the abbreviated balance error scoring system. Athl Train Sports Health Care 2015;7:89-96.

24 Lovell MR, Collin MW, Podell K, et al. ImPACT: immediate post-concussion assessment cognitive testing. Pittsburgh, PA: Neurohealth Systems, LLC, 2000.

25 Heitger MH, Jones RD, Anderson TJ. A new approach to predicting postconcussion syndrome after mild traumatic brain injury based upon eye movement function. Paper presented at the 30th Annual International Conference of the IEEE Engineering in Medicine and Biology Society. Vancouver, BC, 2008. https://ieeexplore.ieee.org/ abstract/document/4649977

26 Galetta KM, Brandes LE, Maki K, et al. The King-Devick test and sports-related concussion: study of a rapid visual screening tool in a collegiate cohort. J Neurol Sci 2011;309:34-9.

27 Smith BW, Dalen J, Wiggins K, et al. The brief resilience scale: assessing the ability to bounce back. Int J Behav Med 2008;15:194-200.

28 Windle G, Bennett KM, Noyes J. A methodological review of resilience measurement scales. Health Qual Life Outcomes 2011;9:8.

29 Gioia GA, Collins M, Isquith PK. Improving identification and diagnosis of mild traumatic brain injury with evidence: psychometric support for the acute concussion evaluation. J Head Trauma Rehabil 2008;23:230-42.

30 Iverson GL, Zasler ND, Lange RT. Post-concussive disorder. In: Zasler ND, Katz DI, Zafont RD, eds. Brain injury medicine: principles and practice. New York, NY: Demos Medical Publishing, 2007: 373-406

31 Bunt S, Didehbani N, Tarkenton T, et al. Sex differences and reporting of SCAT-5 concussion symptoms in adolescent athletes. Clin J Sport Med 2019.

32 Chung JS, Zynda AJ, Didehbani N, et al. Association between sleep quality and recovery following sport-related concussion in pediatrics. J Child Neurol 2019;34:639-45.

33 Demographics.texas.gov.. Population Projections for Texas - Report, 2019. Available: https://demographics.texas.gov/Data/TPEPP/ Projections/Report.aspx?id=41799b21 f88b449e9c16d62b56560547 [Accessed 6 Sep 2019].

34 Henry LC, Elbin RJ, Collins MW, et al. Examining recovery trajectories after sport-related concussion with a multimodal clinical assessment approach. Neurosurgery 2016;78:232-41. 